\title{
Knowledge About Postoperative Pain and Its Management in Surgical Patients
}

\author{
Muhammad Nasir $^{1}$, Aliya Ahmed ${ }^{1}$ \\ 1. Anaesthesiology, Aga Khan University, Karachi, PAK
}

Corresponding author: Aliya Ahmed, aliya.ahmed@aku.edu

\begin{abstract}
Background: Research has shown that more than $50 \%$ of patients have insufficient postoperative pain relief despite the use of multiple pain management modalities. Insufficient pain relief leads to several pathophysiological effects. One of the barriers to optimal pain relief is patient's lack of knowledge regarding the options available for pain management and their potential side effects. In this survey, we evaluated surgical patients' knowledge about postoperative pain and its management in patients undergoing major upper abdominal surgeries at a tertiary care hospital.
\end{abstract}

Methods and Material: This was a cross-sectional survey. A total of 155 patients (18-60 years of age) scheduled to undergo elective major upper abdominal surgery were included after ethical approval and informed consent. Preoperatively, patients were interviewed through a questionnaire regarding knowledge about postoperative pain and its management.

Results: The average age of the patients was $42.97 \pm 13.05$ years. Excellent and good knowledge were observed in $11.61 \%$ and $21.94 \%$ patients, respectively, whereas fair and poor knowledge were seen in $42.58 \%$ and $23.87 \%$, respectively. Inadequate knowledge was more marked regarding analgesic side effects and addiction risk. Education level, history of surgery, and adequate information provision about pain management plan by surgeons preoperatively were significantly associated with a higher level of knowledge about pain and its management (p-value $0.0005,0.002$, and 0.0005 , respectively).

Conclusion: A considerable proportion of patients have inadequate knowledge about their postoperative pain and its management, particularly in areas of side effects and addiction risk.

Received 01/02/2020

Review began 01/07/2020 Review ended 01/07/2020 Published 01/17/2020

๑) Copyright 2020 Nasir et al. This is an open access article distributed under the terms of the Creative Commons Attribution License CC-BY 3.0., which permits unrestricted use, distribution, and reproduction in any medium, provided the original author and source are credited.
Categories: Anesthesiology, Pain Management

Keywords: pain, pain management, postoperative pain, knowledge

\section{Introduction}

A lot of research has gone into the understanding and treatment of postoperative pain in recent times, and several advances have been made in the management of postoperative pain. However, ineffective postoperative pain relief still remains a common problem in health care, and it is estimated that approximately $50 \%-75 \%$ of patients have insufficient pain relief postoperatively [1-3]. One of the barriers to attaining optimal pain relief has been found to be patients' lack of knowledge regarding the options available for pain management and their potential side effects [4-8]. The reason for this is that a patient who is not aware of the available options would not be able to demand for them when in pain. On the other hand, lack of knowledge may lead to unrealistic expectations about the level of pain relief that would be achieved [6]. Thus, when working towards improvement of pain management practices, it would be useful to know the level of patients' knowledge about pain management options and their expected side effects. The gaps identified in knowledge can subsequently be addressed by appropriate educational programs to improve patients' knowledge. This would make patients' expectations about the relief of his pain more realistic. Research has been conducted to assess knowledge of pain and its management in patients suffering from cancer pain to identify gaps and implement educational programs to address them $[7,9,10]$.

Postoperative pain management is a major concern for surgical patients. Ineffective pain relief leads to several pathophysiological and psychological issues that may hinder smooth postoperative recovery [11-14]. Bozimowski has reported that patients having adequate knowledge are more likely to experience positive outcomes [6]. Furthermore, in present-day practice, patients have a right to be involved in all aspects of their pain management $[14,15]$. If surgical patients have adequate knowledge about the options available for postoperative pain relief, they will be better able to realistically discuss the suitable options for their situation and will also be better able to report their satisfaction and/or dissatisfaction levels [16]. To bring about improvement in patients' knowledge regarding their pain management, the areas of lack of knowledge and the reasons behind them need to be assessed. We conducted this survey to determine the knowledge about postoperative pain and its management in patients undergoing major upper abdominal surgery at a tertiary care hospital in a developing country. 


\section{Materials And Methods}

It was a cross-sectional survey and was conducted at a tertiary care hospital of a developing country. Approval was obtained from the institutional Ethics Review Committee, and informed consent was taken from all patients. Sample size was calculated by using the WHO software for sample size calculation. Previous studies have shown that knowledge about postoperative pain is approximately $70 \%-75 \%[7,9,10]$. Using a value of $73 \%$, the estimated sample size was 155 with $95 \%$ confidence interval.

Inclusion criteria to participate in the survey consisted of patients aged between 18 and 60 years scheduled to undergo elective upper abdominal surgery (incisions extending above the umbilicus). Patients who had a history of neurological or psychiatric diseases, had difficulty in communication, those unwilling to participate, and those undergoing emergency procedures were excluded. Patients coming for preoperative evaluation before major upper abdominal surgery and met our inclusion criteria were recruited. One of the authors interviewed all patients in the preoperative clinic before preoperative assessment and filled out a questionnaire. Patient's confidentiality was ensured by assigning code numbers, and data were kept under lock and key by the primary investigator.

\section{Questionnaire}

The questionnaire for this survey was modified from the Patient Pain Knowledge Tool drafted by Borneman et al. for their work on cancer pain (with permission) and the American Pain Society Patient Outcome Questionnaire, which is permitted to be used by the Society $[7,9,17]$. Both these tools have been validated by the respective authors. The questionnaire included information regarding patient demographic data such as age, gender, and education level. There were 10 questions about knowledge of postoperative pain and its management. They included questions about types of pain (acute and chronic), side effects of pain medicines, risk of addiction, pain assessment scales, and treatment options other than opioids (paracetamol, non-steroidal anti-inflammatory drugs, etc.). Each question had true, false, and do not know options. The questionnaire was piloted on five patients and was presented in department academic meeting for input and suggestions before finalization. For the purpose of analysis, each correct answer was given one mark, whereas wrong and do not know options were given a zero. Patients with more than $70 \%$ correct responses were labeled as having excellent knowledge, those with 50\%-69\% correct responses as having good knowledge, 30\%-49\% correct responses were considered fair knowledge, and less than 30\% as poor knowledge.

\section{Statistical analysis}

All statistical analyses were performed using Statistical Package for Social Sciences version 19 (IBM Corp., Armonk, NY). Frequency and percentages were computed for categorical observations like gender, education level, and knowledge of pain and its management. Mean and standard deviation were estimated for age. The chi-square test was applied to observe significant difference in knowledge with respect to gender, education status, and previous surgery. P-value of $\leqslant 0.05$ was considered as significant.

\section{Results}

A total of 155 patients were included in this survey. Overall knowledge about postoperative pain and its management was found to be excellent in $11.61 \%$ (18/155) of the study population, good in $21.94 \%(34 / 155)$ patients, and fair and poor knowledge were observed in $42.58 \%$ (66/155) and $23.87 \%$ of patients (37/155), respectively. Knowledge about postoperative pain and its management with respect to patients' demographics is provided in Table 1. 


\section{Cureus}

\begin{tabular}{|c|c|c|c|c|}
\hline \multirow{2}{*}{ Variables } & \multicolumn{2}{|c|}{ Knowledge about postoperative pain and its management } & \multirow{2}{*}{ Total } & \multirow{2}{*}{ P-value } \\
\hline & Yes & No & & \\
\hline \multicolumn{4}{|l|}{ Age groups } & \multirow{5}{*}{0.510} \\
\hline$\leq 31$ years & $11.00(28.2 \%)$ & $28.00(71.8 \%)$ & 39.0 & \\
\hline $31-40$ years & $9.00(37.5 \%)$ & $15.00(62.5 \%)$ & 24.0 & \\
\hline $41-50$ years & $16.00(42.1 \%)$ & $22.00(57.9 \%)$ & 38.0 & \\
\hline 51-60 years & $16.00(29.6 \%)$ & $38.00(70.4 \%)$ & 54.0 & \\
\hline \multicolumn{4}{|l|}{ Gender } & \multirow{3}{*}{0.104} \\
\hline Male & $12.00(24.5 \%)$ & $37.00(/ 5.5 \%)$ & 49.0 & \\
\hline Female & $40.00(37.1 \%)$ & $66.00(62.3 \%)$ & 106.0 & \\
\hline \multicolumn{4}{|l|}{ Education level } & \multirow{5}{*}{0.0005} \\
\hline Illiterate & $2.00(5.6 \%)$ & $34.00(94.4 \%)$ & 36.00 & \\
\hline High school or less & $10.00(16.9 \%)$ & $49.00(83.1 \%)$ & 59.00 & \\
\hline Under graduate & $19.00(59.4 \%)$ & $13.00(40.6 \%)$ & 32.00 & \\
\hline Graduate and above & $21.00(75 \%)$ & $7.00(25 \%)$ & 28.00 & \\
\hline \multicolumn{4}{|l|}{ Previous surgery } & \multirow{3}{*}{$0.002^{*}$} \\
\hline Yes & $16.00(59.3 \%)$ & $11.00(40.7 \%)$ & 27.00 & \\
\hline No & $36.00(28.1 \%)$ & $92.00(71.9 \%)$ & 128.00 & \\
\hline \multicolumn{4}{|c|}{ Received adequate information about your pain management plan from the surgeon during preoperative visit } & \multirow{3}{*}{$0.0005^{\star}$} \\
\hline Yes & $22.00(64.7 \%)$ & $12.00(35.3 \%)$ & 34.00 & \\
\hline No & $30.00(24.8 \%)$ & $91.00(75.2 \%)$ & 121.00 & \\
\hline
\end{tabular}

TABLE 1: Knowledge about postoperative pain and its management with respect to demographic and clinical factors

Age group and gender were not associated significantly with level of knowledge about postoperative pain management as shown in Table 1. Education level of the patient had a significant association with level of knowledge ( $(\mathrm{=}$ 0.0005), patients who had received a higher education (high school and above) demonstrated more knowledge as compared to those who were less educated or illiterate. In our study, $16.8 \%$ of the patients had a history of previous surgery, and it was found that knowledge about postoperative pain management was significantly higher in patients who had a history of previous surgery $(p=0.002)$. Only $22 \%$ of the participants affirmed that they had received adequate information regarding pain management plans at the preoperative visits to surgery clinic, whereas $78 \%$ said that they were not provided with information about their postoperative pain management plan. Participants who received adequate information about pain management were significantly more knowledgeable as compared to those who did not receive adequate information $(\mathrm{p}=0.0005)$.

Analysis of individual questions was also performed, and it was observed that most of the questions had below $50 \%$ correct response rate as shown in Table 2 . The question with the highest score was related to treatment other than medicines (such as massage, heat, and relaxation) that can help relieve pain. When the question "Is the need to increase the dose of their pain medicine a sign of addiction?" was put forth, only $18.7 \%$ of the patients thought that this was not a sign of addiction, whereas $26.5 \%$ were uncertain of the answer. Only 31.6\% of the patients knew about the pain scales that are used to assess pain severity. Other questions that had less than $50 \%$ correct response rates included questions evaluating patients' knowledge regarding addiction to pain medication, prevention and treatment of their side effects, and importance for doctors and nurses to know the patients' pain severity and characteristics as shown in Table 2. 


\section{Cureus}

\begin{tabular}{|c|c|c|c|}
\hline Questions & $\begin{array}{l}\text { Excellent to good } \\
\text { response (\%) }\end{array}$ & $\begin{array}{l}\text { Fair to poor } \\
\text { response (\%) }\end{array}$ & $\begin{array}{l}\text { Patient did not } \\
\text { know (\%) }\end{array}$ \\
\hline Pain is mainly of two types: acute and chronic & 61.90 & 22.60 & 15.50 \\
\hline Addiction to pain medicine will be caused easily when taking pain medicines & 46.50 & 33.50 & 20.00 \\
\hline Side effects of pain medicines can be prevented and treated & 28.40 & 48.40 & 23.20 \\
\hline It is not important for doctors and nurses to know about your pain & 47.70 & 27.70 & 24.50 \\
\hline The pain that you are feeling can be assessed by using a pain scale & 31.60 & 45.20 & 23.20 \\
\hline A need to increase the dose of your pain medicine is a sign of addiction & 18.70 & 54.80 & 26.50 \\
\hline You can stop your pain medicines suddenly without worrying about side effects & 21.30 & 46.50 & 32.30 \\
\hline $\begin{array}{l}\text { Around the clock dosing of pain medicine means that the medicine will be given on } \\
\text { regular basis, whether you are in pain or not }\end{array}$ & 34.80 & 38.70 & 26.50 \\
\hline Paracetamol and ibuprofen are used for severe pain only & 40.60 & 36.80 & 22.60 \\
\hline Treatment other than medicines can be helpful for relieving pain & 64.50 & 25.20 & 10.30 \\
\hline
\end{tabular}

TABLE 2: Participants' response level to individual questions

\section{Discussion}

This survey was conducted to assess the knowledge about postoperative pain management in patients undergoing major upper abdominal surgery at a tertiary care hospital. These surgeries were selected for the study because they cause moderate-to-severe postoperative pain that requires focused strategies including careful counseling of the patient for effective pain relief. The results revealed deficiencies in knowledge, especially pertaining to the nature of postoperative pain and the methods available to manage it. Scott and Hodson have reported similar results in their study [5]. They concluded that population of Scotland had little or no understanding of the nature of postoperative pain and methods to treat it. They recommend widespread public and professional education to make improvements to this basic clinical problem.

The results of our survey showed that only $33.55 \%$ of patients had excellent to good knowledge, whereas $66.45 \%$ had inadequate (fair to poor) knowledge regarding postoperative pain and its management following major upper abdominal surgeries. These finding are not consistent with the study conducted by Borneman et al. on patients with cancer pain $[7,9]$. They found that $73 \%-85 \%$ of the patients had sufficient knowledge regarding pain management. However, Borneman's study was done on patients already taking pain medication. Our study, on the other hand, was conducted on a patient population who had no prior exposure to postoperative pain and its management except for about $17 \%$ of patients, who had undergone previous surgeries. Moreover, patients included in their study had a better educational background, only $18 \%$ of our study participants were university graduates whereas $23.23 \%$ were completely illiterate.

Our results did not reveal a significant difference in the level of knowledge in context to age and gender. A similar finding was established by the Norwegian study done by Valeberg. However, there was a higher percentage of female patients (68.39\%) in our study compared to almost equal gender distribution in Valeberg's study sample [18].

A significant correlation was found between educational level and the total score of knowledge about pain in our study population. The enrolled population who had graduate level education and above demonstrated better knowledge regarding pain management options than those who had received lower levels of education or were illiterate. Baker et al. found in their research that individuals with higher education actively seeked information regarding their treatment and discussed that information with their physicians, while lower education was found by them to be one of the barriers to receiving and understanding information regarding pain management [8]. Results of our survey demonstrated that patients who had previous surgical exposure had significantly better knowledge regarding postoperative pain management $(\mathrm{p}=0.002)$. Scott and Hodson found a statistically significant difference between patients who underwent previous surgery (51\%) and those who did not $(32 \%)(p=0.001)$ [5]. In their study, patients who had not experienced previous surgery thought simple pain killers such as aspirin, paracetamol, or ibuprofen were sufficient for major surgery, whereas others who had undergone previous surgery had knowledge about narcotic analgesia and knew that narcotics were used most often for postoperative pain management.

In our survey, patients who received adequate information about their pain management plan in the surgical 
clinic during the preoperative visits were more knowledgeable as compared to those who did not receive adequate information $(\mathrm{p}=0.0005)$. Similar findings were observed by Stomberg et al., who concluded that inadequate knowledge about pain management was due to a lack of preoperative information and inadequate preoperative discussions about pain management [19]. They also found that inadequate preoperative discussion regarding pain management correlated with higher postoperative pain [19]. Furthermore, Miaskowski et al. found that educational intervention in cancer patients was effective in good pain management [20]. Two different studies, by Kim et al. on US population and Rustoen et al. on Norwegian population, found that patients who received psychoeducational intervention had an increased overall knowledge of cancer pain management by $21 \%[4,21]$.

More than $50 \%$ of our patients were of the belief that the need to increase the dose of their pain medicine was a sign of addiction. Borneman et al. had similar findings in their study and discovered that the belief that 'use of opioids for pain relief leads to addiction' was the knowledge item which had persistently low scores among their questionnaire items [9]. They found this to be an important barrier to pain management in cancer patients and recommended continued teaching and reinforcement. Their findings indicate that, although patients may have knowledge about pain and its traditional treatment, they are unaware of the adverse effects, and risk of addiction and tolerance. They recommend that these misconceptions regarding pain therapy can be alleviated through implementation of educational programs.

In our findings, the question with the highest knowledge score was related to treatments other than medicines (massage, heat, relaxation, etc.) to help relieve pain. Patients are aware of these options through various sources, such as magazine articles, family, and friends. Despite having knowledge about these strategies, patients often do not make use of them [22]. Becker et al. have identified several barriers to the use of a non-pharmacological method for pain relief [22]. These include fear that it might fail or be harmful, skepticism about its efficacy, belief that it is lower quality/substandard care, lack of motivation, and so on.

Assessment of pain is an essential part of effective pain management. The health care provider must assess patients' pain at regular intervals to ensure that the patient is pain free or ascertain whether action needs to be taken to improve pain management. Patients' understanding and cooperation is required for adequate pain assessment. Only $31.6 \%$ of our patients knew that pain scales are used to assess the severity of pain. Pain is a complex phenomenon that involves physical, psychological, and social variables [23]. Level of coping capacity and emotional states vary in each patient. Some patients may believe that it is noble to suffer in silence and do not inform the caregivers about their pain. It is therefore recommended that surgical patients must be informed preoperatively about the importance of pain assessment for effective pain management and the method that will be used for their pain assessment in the postoperative period should also be explained to them. This would also be an opportunity to improve their perception about the importance of doctors and nurses to know about the severity of their pain and about any side effects that they may have secondary to their medication. Adequate pain relief is essential for the patients to be able to resume activity, maintain a positive attitude, and get adequate sleep following surgery, and this requires knowledge and prioritization on the part of both doctors and nurses [24].

Bozimowski concluded that lack of knowledge about pain and its management is an important barrier to optimal pain relief [6]. Miaskowski et al. suggested that strategies in reducing barriers to pain management require attention to knowledge as well as attitudes about pain [20]. Preoperative interaction between the patient and health care providers seems to be an important tool to provide information about post-operative pain management. Clinicians can utilize patient's responses to this type of questionnaire and focus on individualized teaching to improve this knowledge deficit. Although considerable time and resources will be required to implement such an educational program, this individualized approach will eventually save staff time of physician and nurses and improve patient outcomes.

\section{Conclusions}

The results of our survey demonstrate that patients have limited knowledge with respect to their postoperative pain management, particularly in areas of drugs, addiction risk, and pain scoring. Future research in this area should capture a larger surgical population including patients having different surgical procedures. Moreover, the impact of preoperative patient education regarding pain management practices on improvement in postoperative pain management needs to be studied.

\section{Additional Information}

\section{Disclosures}

Human subjects: Consent was obtained by all participants in this study. Ethical Review Committee the Aga Khan University issued approval 3124-Ane-ERC-14. Animal subjects: All authors have confirmed that this study did not involve animal subjects or tissue. Conflicts of interest: In compliance with the ICMJE uniform disclosure form, all authors declare the following: Payment/services info: All authors have declared that no financial support was received from any organization for the submitted work. Financial relationships: All authors have declared that they have no financial relationships at present or within the previous three years with any organizations that might have an interest in the submitted work. Other relationships: All authors 
have declared that there are no other relationships or activities that could appear to have influenced the submitted work.

\section{References}

1. Nimmaanrat S, Tangtrakulwanich B, Wanasuwannakul T, Boonriong T: Expectations, experiences and attitudes of orthopedic patients undergoing arthroscopic cruciate ligament reconstruction toward postoperative pain and its management. J Med Assoc Thai. 2010, 93:1268-1273.

2. Bajwa SJ: Managing acute post-operative pain: advances, challenges and constraints . Indian J Anaesth. 2017, 61:189-191.

3. Yang MMH, Hartley RL, Leung AA, et al.: Preoperative predictors of poor acute postoperative pain control: a systematic review and meta-analysis. BMJ Open. 2019, 9:e025091. 10.1136/bmjopen-2018-025091

4. Rustøen T, Valeberg BT, Kolstad E, Wist E, Paul S, Miaskowski C: The PRO-SELF৫ pain control program improves patients' knowledge of cancer pain management. J Pain Symptom Manage. 2012, 44:321-330. 10.1016/j.jpainsymman.2011.09.015

5. Scott N, Hodson M: Public perceptions of postoperative pain and its relief . Anaesthesia. 1997, 52:438-442. 10.1111/j.1365-2044.1997.122-az0116.x

6. Bozimowski G: Patient perceptions of pain management therapy: a comparison of real-time assessment of patient education and satisfaction and registered nurse perceptions. Pain Manag Nurs. 2012, 13:186-193. 10.1016/j.pmn.2010.04.004

7. Borneman T, Koczywas M, Sun VC, Piper BF, Uman G, Ferrell B: Reducing patient barriers to pain and fatigue management. J Pain Symptom Manage. 2010, 39:486-501. 10.1016/j.jpainsymman.2009.08.007

8. Baker TA, O'Connor ML, Krok JL: Experience and knowledge of pain management in patients receiving outpatient cancer treatment: what do older adults really know about their cancer pain?. Pain Med. 2014, 15:52-60. 10.1111/pme.12244

9. Borneman T, Koczywas M, Sun V, et al.: Effectiveness of a clinical intervention to eliminate barriers to pain and fatigue management in oncology. J Palliat Med. 2011, 14:197-205. 10.1089/jpm.2010.0268

10. Sun V, Borneman T, Koczywas M, et al.: Quality of life and barriers to symptom management in colon cancer. Eur J Oncol Nurs. 2012, 16:276-280. 10.1016/j.ejon.2011.06.011

11. Gordon DB, de Leon-Casasola OA, Wu CL, Sluka KA, Brennan TJ, Chou R: Research gaps in practice guidelines for acute postoperative pain management in adults: findings from a review of the evidence for an american pain society clinical practice guideline. J Pain. 2016, 17:158-166. 10.1016/j.jpain.2015.10.023

12. Cao X, Elvir-Lazo OL, White PF, Yumul R, Tang J: An update on pain management for elderly patients undergoing ambulatory surgery. Curr Opin Anaesthesiol. 2016, 29:674-682. 10.1097/ACO.0000000000000396

13. Hamilton TW, Athanassoglou V, Mellon S, et al.: Liposomal bupivacaine infiltration at the surgical site for the management of postoperative pain. Cochrane Database Syst Rev. 2017, 2:CD011419. 10.1002/14651858.CD011419.pub2

14. Ramia E, Nasser SC, Salameh P, Saad AH: Patient perception of acute pain management: data from three tertiary care hospitals. Pain Res Manag. 2017, 2017:7459360 . 10.1155/2017/7459360

15. American Society of Anesthesiologists Task Force on Acute Pain Management: Practice guidelines for acute pain management in the perioperative setting: an updated report by the American Society of Anesthesiologists Task Force on Acute Pain Management. Anesthesiology. 2012, 116:248-273. 10.1097/ALN.0b013e31823c1030

16. Sjoling M, Nordahl G, Olofsson N, Asplund K: The impact of preoperative information on state anxiety, postoperative pain and satisfaction with pain management. Patient Educ Couns. 2003, 51:169-176. 10.1016/s0738-3991(02)00191-x

17. Gordon DB, Polomano RC, Pellino TA, et al.: Revised American Pain Society Patient Outcome Questionnaire (APS-POQ-R) for quality improvement of pain management in hospitalized adults: preliminary psychometric evaluation. J Pain. 2010, 11:1172-1186. 10.1016/j.jpain.2010.02.012

18. Valeberg BT, Hanestad BR, Klepstad P, Miaskowski C, Moum T, Rustoen T: Cancer patients' barriers to pain management and psychometric properties of the Norwegian version of the Barriers Questionnaire II. Scand J Caring Sci. 2009, 23:518-528. 10.1111/j.1471-6712.2008.00639.x

19. Stomberg MW, Wickstrom K, Joelsson H, Sjostrom B, Haljamae H: Postoperative pain management on surgical wards--do quality assurance strategies result in long-term effects on staff member attitudes and clinical outcomes?. Pain Manag Nurs. 2003, 4:11-22. 10.1053/jpmn.2003.3

20. Miaskowski C, Dodd M, West C, et al.: Randomized clinical trial of the effectiveness of a self-care intervention to improve cancer pain management. J Clin Oncol. 2004, 22:1713-1720. 10.1200/JCO.2004.06.140

21. Kim JE, Dodd M, West C, et al.: The PRO-SELF pain control program improves patients' knowledge of cancer pain management. Oncol Nurs Forum. 2004, 31:1137-1143. 10.1188/04.ONF.1137-1143

22. Becker WC, Dorflinger L, Edmond SN, Islam L, Heapy AA, Fraenkel L: Barriers and facilitators to use of nonpharmacological treatments in chronic pain. BMC Fam Pract. 2017, 18:41. 10.1186/s12875-017-0608-2

23. Sturgeon JA, Zautra AJ: Social pain and physical pain: shared paths to resilience . Pain Manag. 2016, 6:63-74. $10.2217 /$ pmt.15.56

24. Khatib SK, Razvi SS, Kulkarni SS, Parab S: A multicentre survey of the current acute post-operative pain management practices in tertiary care teaching hospitals in Maharashtra. Indian J Anaesth. 2017, 61:215224. 